\title{
Probabilistic Model to Predict the Outcome in Acute Suicidal Chemical Poisoning Cases From Age and Gender of Patient and Type of Chemical Poison Consumed
}

\author{
Alka Bansal, ${ }^{1}$ Smita Jain, ${ }^{2}$ Ashish Agrawal, ${ }^{3}$ Monica Jain,, Shivankan \\ Kakkar, ${ }^{1}$ Sneha Arora ${ }^{1}$
}

\begin{abstract}
Background: Acute chemical poisoning is a significant global health problem. Chemical poisons include agrochemical, household and industrial poison subtypes. The present study used a probabilistic model based on age, gender and type of poison consumed by the patient to predict the outcome in acute suicidal poisoning cases. Material and methods: A prospective observational study was conducted at emergency department of SMS Hospital, Jaipur, India, from January 2019 to February 2020. Patients over 15 years of age with poisoning severity score 2 or above were included in the study. Probabilistic model was used to predict the outcome measured in terms of cure, death and left against medical advice (LAMA) using Minitab 14.

Results: Poisoning cases were $0.32 \%$ of all emergency presentations. Out of them, $857(59.6 \%)$ had consumed chemical poison. Their mean age was 32 years and men to women ratio was 1.22 . Agrochemical subtype was most common followed by household and industrial poisoning. Analysis by Probabilistic model showed that person between 30-60 years is more likely to be cured and chances of death and LAMA are highest in age group 60-75. Gender-wise, men have higher possibility for recovery. Besides, a person has highest chances of recovery in case of household poisons; death is most common in industrial poisons and LAMA in agrochemical poisons.

Conclusion: The study concluded that in poisoning, patients' basic information like age, gender, type of poison consumed can be used to identify high death probability and LAMA risk patients. It will assist in designing and monitoring the most effective strategies for them.
\end{abstract}

Key words: Cure; Death; LAMA; Outcome; Poisoning; Probabilistic model.
(1) Department of Pharmacology, SMS Medical College, Jaipur-302004, Rajasthan, India.

(2) Department of Mathematics and Statistics, JECRC University, JECRC university, Jaipur-302018, Rajasthan, India.

(3) Ashish's Clinic, A-207 Triveni Nagar, Gopalpura Bypass, Jaipur-302018, Rajasthan, India.

Correspondence:

SHIVANKAN KAKKAR

E: drshivankankakkar@gmail.com T: +919828276839

\section{ARTICLE INFO}

\section{Received: 4 May 2021} Revision received: 21 May 2021 Accepted: 23 May 2021

\section{Introduction}

Poison is any substance that by means of its exposure due to ingestion, inhalation or contact can injure, kill, or impair normal physiological function in humans and produce general or local damage in the body. ${ }^{1,2}$ Acute poisoning either with single or multiple exposures within 24 hours is a significant global health problem responsible for large number of emergency presentations. ${ }^{3}$ According to WHO in 2012 , it ranked $45^{\text {th }}$ in total death worldwide, while in India, it accounted for the fourth common cause of mortality. ${ }^{1,2}$

Poisons can be divided into four major categories: chemical poisons, drugs and medications 
overdose, poisons of biologic origin and radiation. Chemical poisons include agricultural, household and industrial poisons subtypes. Organophosphates, carbamates, paraquat, rodenticides, chlorinated hydrocarbons, pyrethroid and fertilisers are various types of agrochemicals. Household poisons are products used in kitchens, bathrooms and day to day life like detergents, carbon tetrachloride, naphthalene, boric acid, oxalic acid, bleaching agents, chlorates, hydrogen peroxide etc. Industrial poisons include organic and inorganic acidic and alkali corrosives, hydrocarbons, oxidising agents, alcohols, glycols and metallic poisons. ${ }^{4,5}$

Whether taken intentionally, forcibly or accidentally, chemical poisoning is commonly found in all age groups and in both genders. Also it is on rising trend due to ever increasing use of chemicals with industrial and agricultural field revolution in recent years combined with lifestyle and behaviour change, easy availability, unrestricted sale and low cost. ${ }^{6}$ Though many studies regarding clinic-epidemiologic pattern of poisoning are available, only few of them explore the possible relationship between patient's basic characteristics, product used for poisoning and probable outcome. ${ }^{7,8}$ Hence, this study was exclusively planned with following objective.

\section{Material and methods}

A prospective observational study was conducted at emergency department of SMS hospital, a premier tertiary care institute of North India from January 2019 to February 2020, after the approval of the study protocol by the institutional ethics committee via letter No 2684MC/ EC/2016 dated 30/9/16 and in continuation of STROBE guidelines.

All patients above 15 years of age presenting as acute suicidal poisoning cases of chemical subtype (ie agrochemical, household and industrial) and belonging to grades 2 or above for The poisoning severity score (PSS) at the time of presentation were included in the study after patient's own or their guardian's consent (if they were incapable of giving so due to their illness) was obtained.

The PSS was developed by the European Association of Poisons Centres and Clinical Toxicologists
(EAPCCT), the International Programme on Chemical Safety (IPCS), and the Commission of the European Union between 1990 and 1994 to provide a simple and reliable scoring system to describe poisonings and define their severity. It classifies poison cases into four grades (also known as scores) $0,1,2,3,4$. Score 0 means no symptoms/signs related to poisoning; 1 means mild, transient, and spontaneously resolving symptoms/signs; score 2 stands for moderately pronounced/prolonged symptoms/signs; score 3 identifies severe life threatening symptoms/ signs and score 4 means fatal cases attributed to poison. It is to clarify here that PSS is clinically based and do not depend on dose and nature of poison consumed..$^{10,11}$

Drug overdoses and poisons of biologic origin as in stings, bites and food poisoning were excluded from the study as in drug overdose, patients usually have associated chronic psychiatric and biologic, radiation origin poisons are mainly accidental. Children ( $<15$ years) were also excluded as this hospital cares to adults only.

The data pertaining to patient's age, gender and poison consumed was collected. Data was analysed using software Minitab 14, Pennsylvania, USA. Descriptive data was expressed in terms of numbers and percentages. Chi-squared test was applied to find association between age, gender, type of poison consumed and final outcome of patient measured in terms of lethal outcome, recovery or left against medical advice (LAMA). Probabilistic model was used to predict the outcome based on rest three parameters.

\section{Results}

Total 1,427 cases were found to be related to poisoning among the 441,204 patients who visited emergency department during 14 months of study period $(0.32 \%)$. Out of them 857 cases of acute suicidal poisoning by chemicals were identified making $58.8 \%$ of total poisoning cases. Remaining 570 patients were either accidental or homicidal in case of chemical or caused by drug overdose / poison of biologic origin/ radiation. Men outnumbered women in ratio 1.22.

Mean age in the both sexes was 32 years. As shown in Table 1, amongst chemicals, agrochemicals were most commonly used in $59.6 \%$ of over- 
Table 1: Summary of acute chemical poisoning cases

\begin{tabular}{|c|c|c|c|c|c|}
\hline & \multicolumn{4}{|c|}{ Poison Type - N (\%) } & \multirow[b]{2}{*}{ p-value } \\
\hline & Agrochemical & Household & Industrial & Total & \\
\hline \multicolumn{6}{|c|}{ Gender } \\
\hline Female & $224(43.84)$ & $97(47.55)$ & $65(45.77)$ & $386(45.04)$ & \multirow{2}{*}{$p=0.654$} \\
\hline Male & $287(56.16)$ & $107(52.45)$ & $77(54.23)$ & $471(54.96)$ & \\
\hline \multicolumn{6}{|l|}{ Outcome } \\
\hline Cure & $388(75.93)$ & $159(77.94)$ & $100(70.42)$ & $647(75.49)$ & \multirow{3}{*}{$p=0.247$} \\
\hline Death & $81(15.85)$ & $31(15.20)$ & $33(23.24)$ & $145(16.92)$ & \\
\hline LAMA & 42 (8.22) & $14(6.86)$ & $9(6.34)$ & 65 (7.58) & \\
\hline \multicolumn{6}{|l|}{ Age Groups* } \\
\hline $15-30$ & 305 (59.69) & $119(58.33)$ & $82(57.75)$ & $506(59.04)$ & \multirow{4}{*}{$p=0.869$} \\
\hline $30-45$ & $144(28.18)$ & $57(27.94)$ & $46(32.39)$ & $247(28.82)$ & \\
\hline $45-60$ & $29(5.68)$ & $11(5.39)$ & $7(4.93)$ & $47(5.48)$ & \\
\hline $60-75$ & $33(6.46)$ & $17(8.33)$ & $7(4.93)$ & $57(6.65)$ & \\
\hline Total & 511 (59.62) & $204(23.80)$ & $142(16.56)$ & $857(100.00)$ & \\
\hline
\end{tabular}

${ }^{*}$ For making the age group interval, both upper and lower limit for the first and last class were considered and excluded the lower limit for the middle two classes; LAMA: left against medical advice.

all cases and also in all age groups followed by household and industrial poisons. Fifty-nine percentage of patients were between 15-30 years of age succeeded by 30-45 years of age group. By and large mortality was seen in $16.9 \%$ of total cases with considerable $7.6 \%$ patients who left the hospital against medical advice (LAMA).

\section{Statistical analysis}

To find the association between all the factors: age group, gender, outcome, poison type; Chisquared test was applied. As shown in Table 1 and 2 , p-value for all the factors was greater than 0.05 (level of significance in this study), hence it was concluded that none of them affected each other. Then the data was evaluated using conditional probabilistic model. For it first the events were defined as given below:

A = Outcome; A1: Cured, A2: Death, A3: LAMA B = Poison type; B1: Agrochemical, B2: Household, B3: Industrial

$\mathrm{C}=$ Gender; C1: Men, C2: Women

$\mathrm{D}=$ Age group; D1: 15-30, D2: 30-45, D3: 45-60, D4: 60-75

Then the formula was applied using software. Results obtained have been summarised in Table 3 .

It can be interpreted from values shown in Table 3, that according to probabilistic model, type of poison consumed affected the outcome of patient. A person randomly selected from the population has highest chances of cure if he/she has consumed household poison, highest chances of death if he/she has taken industrial poison and the highest chances of LAMA if he/she has consumed agrochemical poison.
Table 2: Age-wise distribution of outcome

\begin{tabular}{|c|c|c|c|c|c|}
\hline & \multicolumn{4}{|c|}{ Outcome - N (\%) } & \multirow[b]{2}{*}{ p-value } \\
\hline & Cured & Death & LAMA & Total & \\
\hline \multicolumn{6}{|l|}{ Age (years) } \\
\hline $15-30$ & $382(75.49)$ & $84(16.60)$ & $40(7.91)$ & $40(7.91)$ & \multirow{4}{*}{$p=0.446$} \\
\hline $30-45$ & $191(77.33)$ & $37(14.98)$ & $19(7.69)$ & $19(7.69)$ & \\
\hline $45-60$ & $36(76.60)$ & $10(21.28)$ & $1(2.13)$ & $1(2.13)$ & \\
\hline $60-75$ & $38(66.67)$ & $14(24.56)$ & $5(8.77)$ & $5(8.77)$ & \\
\hline Total & 647 (73.94) & 145 (16.57) & $65(7.43)$ & $857(100.00)$ & \\
\hline
\end{tabular}

Table 3: Conditional probabilities values to depict effect of age, gender and type of poison consumed on final outcome of patients

\begin{tabular}{|c|c|c|c|}
\hline \multicolumn{4}{|c|}{ Conditional probabilities } \\
\hline \multicolumn{4}{|c|}{ Outcome (A) } \\
\hline Poison Type (B) & Cure (A1) & Death (A2) & LAMA (A3) \\
\hline Agrochemical (B1) & 0.76 & 0.16 & 0.08 \\
\hline Household (B2) & 0.78 & 0.15 & 0.07 \\
\hline Industrial (B3) & 0.71 & 0.23 & 0.06 \\
\hline \multicolumn{4}{|l|}{ Gender (C) } \\
\hline Men (C1) & 0.76 & 0.16 & 0.08 \\
\hline Women (C2) & 0.74 & 0.18 & 0.08 \\
\hline \multicolumn{4}{|l|}{ Age Group (D) } \\
\hline $15-30(\mathrm{D} 1)$ & 0.75 & 0.17 & 0.07 \\
\hline $30-45(\mathrm{D} 2)$ & 0.77 & 0.15 & 0.08 \\
\hline $45-60$ (D3) & 0.77 & 0.21 & 0.02 \\
\hline $60-75$ (D4) & 0.66 & 0.25 & 0.09 \\
\hline
\end{tabular}

Same model revealed that men have higher possibility for recovery and women are more prone to lethal outcome in acute chemical suicidal poisoning cases. Furthermore, it was also found that a randomly selected person has highest chances of cure if he/she is between 30-60 years of age and highest chances of death and LAMA if he/she is from the age group 60-75.

\section{Discussion}

This study found $0.32 \%$ consultations in emergency were related to poisoning. Out of them 58.8 $\%$ were exclusively pertinent to acute exposure of chemicals. A total of $59 \%$ of patients included in the study were between 15-30 years of age and the overall men to women ratio was 1.22. Many congruent studies have also reported 0.3 to $0.6 \%$ of emergency presentations due to poisons., ${ }^{72,13}$

As in this study, most studies found maximum incidence of poisoning in age group less than 40 years and with men predominance, though, Ethiopia reports mixed results related to gender pre- 
ponderance in different studies. ${ }^{1,12-14}$ The suggested explanation to high incidence of poisoning in men is that they are comparatively more exposed to stress and strain due to myriad reasons like financial difficulties, loss of job, discord at home and workplace etc, leading to mental vulnerability and impulsiveness of youth population. 59.6\% cases in the present study had agrochemical poisoning. Similar findings were reported by other researchers. ${ }^{1,12-14}$ However, as per analysis of calls to National Poisons Information Centre, New Delhi, $44.1 \%$ of poison related calls were due to household agents followed by drugs (18.8\%), agricultural pesticides (12.8\%), industrial chemicals $(8.9 \%)^{2}$

As the outcome was concerned, $16.9 \%$ of patients in the present study succumbed to poisoning, $7.6 \%$ were LAMA cases and rest $75.5 \%$ were cured with maximum cure rate in household poisons (77.9\%). These results were in partial agreement with study by Sharminder et al from India who also mentioned overall mortality of $9.7 \%$, LAMA in $3.1 \%$ and least case fatality in household poisons. ${ }^{12}$ However, Getie et al from Ethiopia found $93.3 \%$ poison cases were cured, as against only $63 \%$ of cure incidence in another study from the same country. ${ }^{13,14}$

Analysis by probabilistic model in this study revealed advanced age to be an independent predictor of mortality (Table 3) as well as LAMA. These findings were in concordance with those by Gudduz et al, who also found higher survival in younger patients. ${ }^{15}$ Accumulation of the toxins in the body owing to the increased amount of fat tissue and their slower metabolism by liver with aging might be responsible for it. Moreover, the propensity to respiratory failure, an important cause of mortality, also increases with age. However, no study to compare the high incidence of LAMA in elderly population could be found.

Contradictory to the findings presented in this paper where men had comparatively more cure rate and women showed high probability of death, Reddy et al and Lee et al reported men as an independent variable contributing to increased mortality rate (odds ratio up to 2.5 ). ${ }^{16,17}$ However, Munera Khan et al found no difference in gender-based outcome of poisoning. ${ }^{18}$

Consumption of industrial poison in the present study was connected to highest mortality rate followed by agrochemical and household poisons in that order. Bhadade et al had similar findings that chemical poisoning with methanol, kerosene, diesel, phenyl (industrial poisons) were associated with high mortality in $34.31 \%$ cases followed by pesticides (agrochemical) in $25 \%$ patients. ${ }^{1}$ However, in study by Shan et al the mortality rate between patient groups ingesting different types of chemicals did not differ.$^{19}$ One study reported surfactant group (household) with an unexpectedly high mortality rate of 75 $\%$, but surfactant cases in total were the least common, accounting for only $5 \%$ of cases. ${ }^{20}$

\section{Conclusion}

The study concluded that elderly population and those who consume industrial poison are at higher probability to succumb to poison in contrast to patients between $30-45$ years of age and consumers of household poisons who have maximum chances of recovery. Identification of high death and LAMA risk patients on the basis of basic information soon after presentation will eventually be helpful in designing and monitoring the most effective strategies for them.

\section{Strengths of study}

It is a novel study of its own kind to show that simple variables like age, gender and knowledge about type of poison consumed can be used as an outcome predictor in acute chemical poisoning cases.

\section{Limitations of study}

Other factors like socioeconomic status, marital status, reason of poisoning, seasonal changes were not considered for the sake of simplicity, saving time and due to lack of reliable information. 


\section{Acknowledgements}

None.

\section{Conflict of interest}

None.

\section{References}

1. Bhadade R, deSouza R, Gangawane S. Analysis of poisoning in urban setting: a single centre study. J Assoc Physicians India 2019 Apr;67(4):57-61.

2. Asawari R, Atmaram P, Bhagwan K, Priti D, Kavya S, Jabeen GA. Toxicological pattern of poisoning in urban hospitals of western India. J Young Pharm 2017;9(3):315.

3. Lee HL, Lin HJ, Yeh SY, Chi CH, Guo HR. Etiology and outcome of patients presenting for poisoning to the emergency department in Taiwan: a prospective study. Hum Exp Toxicol 2008 May;27(5):373-9.

4. Ministry of health, Singapore. Management of drug overdose and poisoning. Guidelines [Internet][Accesed: 19May-2021]. Available at: https://www.moh.gov.sg/docs/ librariesprovider4/guidelines/cpg_management-ofdrug-overdose-and-poisoning-may-2000.pdf.

5. Indu TH, Raja D, Ponnusankar S. Toxicoepidemiology of acute poisoning cases in a secondary care hospital in rural South India: A five-year analysis. J Postgrad Med 2015 Jul-Sep;61(3):159-62.

6. Rafiuddin M, Hussain SS, Hashmi SA, Qureshi SAA, Ali MA, Rao UR, et al. A prospective study on different types of poisoning cases and their outcome at tertiary care hospital. Int J Adv Pharm Med Bioallied Sci 2017;2017:126.

7. Chatterjee S, Verma VK, Hazra A, Pal J. An observational study on acute poisoning in a tertiary care hospital in West Bengal, India. Perspect Clin Res 2020 AprJun;11(2):75-80.

8. Anthony L, Kulkarni C. Patterns of poisoning and drug overdosage and their outcome among in-patients admitted to the emergency medicine department of a tertiary care hospital. Indian J Crit Care Med 2012 Jul;16(3):130-5.

9. Ramaya A, Andhuvan G, Raghupathi V. Observational study on poison cases in a tertiary care hospital. Int J Pharm Pharm Sci 2019;11(4):80-3.

10. Yuan S, Gao Y, Ji W, Song J, Mei X. The evaluation of acute physiology and chronic health evaluation II score, poisoning severity score, sequential organ failure assessment score combine with lactate to assess the prognosis of the patients with acute organophosphate pesticide poisoning. Medicine (Baltimore) 2018 May;97(21):e10862.
11. WHO. Poisoning severity score. [Internet]. [Accesed: 19May-2021]. Available at: https://www.who.int/ipcs/poisons/pss.pdf.

12. Kaur S, Gupta S, Sadiq S, Khajuria V. Spectrum of acute poisoning: A retrospective observational study in a tertiary care hospital in North India. Natl J Physiol Pharm Pharmacol 2016;6:247-50.

13. Endayehu Y, Shenkutie E. Magnitude of acute poisoning and associated factors in Debretabor general hospital, Ethiopia. J Clin Toxicol 2019;9:429.

14. Getie A, Belayneh YM. A retrospective study of acute poisoning cases and their management at emergency department of Dessie Referral Hospital, Northeast Ethiopia. Drug Healthc Patient Saf 2020 Mar 5;12:41-8.

15. Gündüz E, Dursun R, Icer M, Zengin Y, Güllü MN, Durgun $\mathrm{HM}$, et al. Factors affecting mortality in patients with organophosphate poisoning. J Pak Med Assoc 2015 Sep;65(9):967-72.

16. Reddy BS, Skaria TG, Polepalli S, Vidyasagar S, Rao M, Kunhikatta V, et al. Factors associated with outcomes in organophosphate and carbamate poisoning: a retrospective study. Toxicol Res 2020 Feb 7;36(3):257-66.

17. Lee HL, Lin HJ, Yeh ST, Chi CH, Guo HR. Presentations of patients of poisoning and predictors of poisoning-related fatality: findings from a hospital-based prospective study. BMC Public Health 2008 Jan 8;8:7.

18. Khan M, Khurram M, Raza S. Gender based differences in patients of poisoning managed at a Medical Unit. J Pak Med Assoc 2019 Jul;69(7):1025-8.

19. Shan L, Kwan Leong AY, Choi Kin Man D, Chi Keung C. Factors that affect mortality in local patients who ingested common household cleansing products and required intubation. Hong Kong J Emerg Med 2020;27(6):334-43.

20. Rajbanshi LK, Arjyal B, Mandal R. Clinical profile and outcome of patients with acute poisoning admitted in intensive care unit of tertiary care center in Eastern Nepal. Indian J Crit Care Med 2018 Oct;22(10):691-6. 